\title{
An Ultrathin Cobalt-Iron Oxide Catalyst for Water Oxidation on Nanostructured Hematite Photoanodes
}

Received 00th January 20xx Accepted 00th January 20xx

DOI: $10.1039 / \times 0 x \times 00000 x$

www.rsc.org/

\author{
Laurent Liardet, ${ }^{a}$ Jordan E. Katz, ${ }^{a, b}$ Jingshan Luo, ${ }^{c, d}$ Michael Grätzel ${ }^{c}$ and Xile Hu, ${ }^{\text {a,* }}$
}

The harvesting of sunlight by a photoelectrochemical (PEC) cell to split water into hydrogen and oxygen is an attractive strategy to store solar energy in the form of chemical bonds. The oxygen evolution reaction (OER) remains a bottleneck for the development of efficient PEC devices. Here we report a photoelectrochemical method to homogeneously deposit a cobalt-iron oxide $\left(\mathrm{CoFeO}_{\mathrm{x}}\right)$ catalyst on a nanostructured hematite photoanode. An ultrathin catalyst layer $(<1 \mathrm{~nm})$ yielded a 200-mV cathodic shift of onset potential and a photocurrent density of 1.6 and $2.5 \mathrm{~mA} \mathrm{~cm}^{-2}$ at $1.0 \mathrm{~V}$ and $1.23 \mathrm{vs}$ RHE in $1 \mathrm{M}$ $\mathrm{KOH}$, respectively. We investigated the enhancement of photoactivity induced by the addition of the $\mathrm{CoFeO}_{\mathrm{x}}$ layer by impedance spectroscopy, photoluminescence, and by using $\mathrm{H}_{2} \mathrm{O}_{2}$ as a hole scavenger. This work points to the effective utilization of subnanometric coatings as efficient catalyst overlayers to enhance the OER activity of photoanodes. .

\section{Introduction}

The production of solar fuels, such as hydrogen gas, could address the energy crisis that the world faces in the coming years. ${ }^{1}$ To reach this goal, the water splitting reaction $\left(2 \mathrm{H}_{2} \mathrm{O} \rightarrow\right.$ $2 \mathrm{H}_{2}+\mathrm{O}_{2}$ ) is of great interest. Sunlight can be used to provide the necessary energy for splitting water $\left(E_{\mathrm{rxn}}=-1.23 \mathrm{~V}\right)$. This process, also known as artificial photosynthesis, is possible with high efficiency by using photelectrochemical water splitting devices, such as tandem cells. ${ }^{2}$ Multiple devices have been demonstrated, with solar to hydrogen efficiencies (STH) of up to $18 \%{ }^{3}$ However, these high efficiency systems typically employ photoabsorbers and catalysts composed of expensive and scarce elements, making them poorly suited for large-scale applications. ${ }^{4}$ The maturation of photoelectrochemical devices has been hindered by the difficulty of finding materials that are inexpensive, earth-abundant, stable under reaction conditions, and that lead to efficient overall solar energy conversion.

Hematite $\left(\alpha-\mathrm{Fe}_{2} \mathrm{O}_{3}\right)$, which is both earth abundant and nontoxic, is a promising photoanode material for water oxidation due to its favorable bandgap. Despite these beneficial attributes, hematite has several intrinsic limitations that prevent this material from reaching its maximum photocurrent density of $12.6 \mathrm{~mA} / \mathrm{cm}^{2}$ under AM $1.5 \mathrm{G}$ solar illumination. ${ }^{5}$ First, a short hole diffusion length $(<4 \mathrm{~nm})$, in addition to a low absorption coefficient, only allows the holes created close to the surface to be collected. Nanostructured architectures have been proposed to address these material limitations.6,7 For example, the structure of nanocauliflower hematite

\footnotetext{
a. Laboratory of Inorganic Synthesis and Catalysis, Institute of Chemical Sciences Engineering, École Polytechnique Fédérale de Lausanne (EPFL), ISIC-LSCI, 1015 Lausanne, Switzerland.

b. Department of Chemistry and Biochemistry, Denison University, $100 \mathrm{~W}$. College St., Granville, $\mathrm{OH}$ 43023, USA

c. Laboratory of Photonics and Interfaces, Institute of Chemical Sciences and Engineering, École Polytechnique Fédérale de Lausanne (EPFL), ISIC-LPI, 1015 Lausanne, Switzerland

d. Institute of Photoelectronic Thin Film Devices and Technology, College of Electronic Information and Optical Engineering, Nankai University, Tianjin 300350, China

† Electronic Supplementary Information (ESI) available: Supplementary figures. See DOI: 10.1039/x0xx00000x

* Correspondence to: xile.hu@epfl.ch
}

The manuscript was written through contributions of all authors and they have given their approval to the final version of the manuscript. photoanodes deposited by atmospheric pressure chemical vapor deposition (referred as APCVD hematite in this work) were finely tuned to be composed of nanocrystals forming a dendritic structure with features of $10-20 \mathrm{~nm}$. With this feature size and a space charge region close to $5 \mathrm{~nm}$ (for highly Si-doped APCVD hematite), this nanostructure is optimal for efficient separation of electrons and holes. Most of photogenerated holes will thus reach the semiconductor/electrolyte interface. ${ }^{6,8}$ Second, the water splitting reaction has a kinetic bottleneck that arises from its four-electron oxidative half-reaction: the oxygen evolution reaction (OER). The sluggish OER kinetics on the hematite surface limit its efficiency as a photoanode. Due to the limitations previously cited, the photocurrent onset potential is much more positive than the flat-band potential of hematite (0.4-0.6 V vs RHE for Si-doped hematite $\left.{ }^{9}\right)$ and is generally not observed below $0.8-1.0 \mathrm{~V}$ vs RHE. ${ }^{8,10}$

The deposition of an OER catalyst on the surface of hematite can decrease the onset potential by improving the charge transfer kinetics.11-14 Among OER catalysts, the cobalt phosphate "Co-Pi" catalyst has been extensively studied. ${ }^{10,14}$ Electrodeposition of Co-Pi yielded a cathodic shift of the OER photocurrent onset potential. Furthermore, a photo-assisted electrodeposition route was developed and resulted in Co-Pi films with superior activity due to a more uniform layer by depositing only onto areas that produce photogenerated holes, thereby avoiding the creation of catalyst nodules and islands. In the present work, we used a similar strategy to produce a thin and uniform layer of $\mathrm{CoFeO}_{x}$ that, compared to the photoelectrodeposited Co-Pi, yielded an earlier onset potential and a higher photocurrent density at $1.0 \mathrm{~V}$ vs RHE (vide infra).

Our group recently reported an oxidative electrodeposition method to produce various unary and binary transition metal oxides made of earth-abundant elements such as $\mathrm{NiO}_{x}, \mathrm{NiFeO}_{x}$, $\mathrm{CoO}_{x}, \mathrm{MnO}_{x}$ and $\mathrm{CoFeO}_{x}$. Among them, $\mathrm{CoFeO}_{x}$ exhibited the lowest overpotential, highest turnover frequency and mass activity in alkaline solutions $(1 \mathrm{M} \mathrm{KOH}) .{ }^{15} \mathrm{NiFeO}_{x}$, was also found to be a highly active OER catalyst when photoelectrodeposited on hematite anodes and was reported in a previous report by our group. ${ }^{12}$ For these reasons, we decided to explore $\mathrm{CoFeO}_{x}$ anodically photoelectrodeposited on hematite. Despite several studies on the electrocatalytic activity of $\mathrm{CoFeO}_{x}$ for water oxidation, few reports of this oxide on the surface of hematite have been described. ${ }^{16-19}$ In these reports, the function of $\mathrm{CoFeO}_{\mathrm{x}}$ varies substantially depending on its thickness and the 
type of hematite used. In the present work, we deposited $\mathrm{CoFeO}_{x}$ on nanocauliflower hematite photoanodes grown by atmospheric pressure chemical vapor deposition (APCVD). To avoid competitive light absorption by the catalyst layer, we developed a photo-assisted electrodeposition method that produced an optically transparent, ultrathin $\mathrm{CoFeO}_{\mathrm{x}}$ layer with high OER activity.

\section{Experimental}

All reagents were purchased from commercial sources and used without additional purification. $18.2 \mathrm{M} \Omega \cdot \mathrm{cm}$ Millipore deionized water was used to prepare all the solutions.

\subsection{Photoelectrochemical experiments}

All electrochemical experiments (deposition of catalyst and photoelectrochemical characterization) were performed by using an Autolab PGSTAT302N potentiostat/galvanostat (Metrohm). Electrodes were illuminated from the front side (photoanode/electrolyte interface) with a 450-W Xenon lamp (LAX 1450, Müller Electronik-Optik) equipped with a KG3 filter ( $3 \mathrm{~mm}$, Schott) in order to simulate the AM 1.5G spectrum. The light intensity at the electrode surface was adjusted to $100 \mathrm{~mW}$ $\mathrm{cm}^{-2}$ with a calibrated Si solar cell (Newport, calibrated by Newport Corporation PV Lab)).

A three-electrode setup was used with the hematite substrate as the working electrode, a platinum wire (for OER measurements) or a titanium wire (for deposition of the $\mathrm{CoFeO}_{x}$ catalyst) as the counter electrodes, and a $\mathrm{Ag} / \mathrm{AgCl}$ (sat. $\mathrm{KCl}$ ) reference electrode. The hematite substrate was connected to the working electrode contact with a crocodile clip. All measured potentials were converted to the reversible hydrogen electrode scale $(\mathrm{RHE})$ by using the formula $E(\mathrm{RHE})=E(\mathrm{Ag} / \mathrm{AgCl})$ $+0.197+0.0592 \cdot \mathrm{pH}$. The surface area of the hematite electrodes was delimited with black epoxy glue (Loctite EA9461), with values typically between 0.07 and $0.15 \mathrm{~cm}^{2}$.

Photocurrent onset potentials were determined by extrapolating to zero current the linear portion of the J-V curve between 0.5 and $1.5 \mathrm{~mA} \mathrm{~cm}$ cm $^{-2} .20$ Photovoltages were determined by subtraction of the potentials to reach $0.3 \mathrm{~mA} \mathrm{~cm}$ ${ }^{2}$ under dark and illumination conditions, respectively. ${ }^{21}$

\subsection{APCVD hematite photoanode preparation}

An atmospheric pressure vapor deposition process (APCVD) was used to prepare the silicon-doped cauliflower hematite samples. The procedure has been described previously by our group. ${ }^{13}$ Briefly, fluorine-doped tin oxide substrates (FTO, TEC 15 , Sigma-Aldrich) were put on a hot plate at $545^{\circ} \mathrm{C}$ in air for 90s. Argon was bubbled through tetraethyl orthosilicate (TEOS, $>99.0 \%$, Aldrich) and iron pentacarbonyl $\left(\mathrm{FeCO}_{5},>99.99 \%\right.$, Aldrich). For the first $90 \mathrm{~s}$, only TEOS vapors were carried from the bubbler and mixed with a flow of air over the hot FTO substrate to form a $\mathrm{SiO}_{2}$ underlayer, and then TEOS and iron pentacarbonyl vapors were mixed together to grow the nanostructured cauliflower Si-doped hematite for another $90 \mathrm{~s}$. The as-prepared hematite was left on the hot plate for an additional $90 \mathrm{~s}$ as an annealing step. The $\mathrm{Fe}_{2} \mathrm{O}_{3}$ photoanodes were later thermally activated in air on a hot plate for $20 \mathrm{~min}$ at $300{ }^{\circ} \mathrm{C}$ to increase reproducibility between samples. The top edge of the photoanodes were washed with $\mathrm{HCl} 6 \mathrm{M}$ prior to catalyst deposition to remove all traces of $\mathrm{Fe}_{2} \mathrm{O}_{3}$ in order to minimize contact resistance with the crocodile clip.

\section{$2.3 \mathrm{Al}_{2} \mathrm{O}_{3}$ overlayer}

The deposition of $\mathrm{Al}_{2} \mathrm{O}_{3}$ was performed in order to improve the performance of the APCVD nanostructured hematite photoanodes. Slightly modified conditions from those previously reported were used. ${ }^{22}$ The $\mathrm{Fe}_{2} \mathrm{O}_{3}$ photoanodes were loaded in a custom-made hot-wall ALD system with the vacuum chamber heated at $130{ }^{\circ} \mathrm{C}$. Six cycles were used to deposit thin $\mathrm{Al}_{2} \mathrm{O}_{3}$ layers. Each cycle was composed of a 0.05 -s pulse of trimethylaluminum (TMA, >98\%, Strem Chemicals INC) followed by $15 \mathrm{~s}$ of nitrogen purging, and then by a 0.5-s pulse of $\mathrm{H}_{2} \mathrm{O}_{2}$ ( 50 wt. \%, Sigma-Aldrich) followed by $15 \mathrm{~s}$ of nitrogen purging. The nitrogen flow was kept a $20 \mathrm{~mL} \mathrm{~s}^{-1}$ during the deposition. The growth per cycle rate of the ALD process was $0.19 \mathrm{~nm}$ per cycle. After the ALD deposition, the samples were annealed for $5 \mathrm{~min}$ at $350^{\circ} \mathrm{C}$ in air on a hot plate. Control samples without $\mathrm{Al}_{2} \mathrm{O}_{3}$ were also annealed with the same procedure.

\subsection{Catalyst deposition}

For the deposition of the $\mathrm{CoFeO}_{x}$ catalyst, an aqueous solution containing $16 \mathrm{mM}$ of cobalt(II) chloride $\left(\mathrm{CoCl}_{2}\right.$, anhydrous, $>98 \%$, Fluka) and $5 \mathrm{mM}$ of iron(III) sulfate $\left(\mathrm{Fe}_{2}\left(\mathrm{SO}_{4}\right)_{3}\right.$, hydrate, $97 \%$, Sigma-Aldrich) was prepared in $0.1 \mathrm{M}$ sodium acetate (anhydrous, >99\%, Sigma-Aldrich). The hematite substrate was immersed in the as-prepared solution and the deposition of $\mathrm{CoFeO}_{x}$ was performed by linear sweep voltammetry (LSV), scanning the potential from 1.1 to $1.7 \mathrm{~V}$ vs RHE at $200 \mathrm{mV} \mathrm{s}^{-1}$ (typically for 1-10 sweeps) under simulated AM 1.5G illumination. The hematite substrate was fully illuminated and the deposition of the $\mathrm{CoFeO}_{\mathrm{x}}$ occurred on the whole substrate area (ca. $1.5 \mathrm{~cm}^{2}$ ). Only after deposition, the surface was delimited by black epoxy glue (Loctite EA9461) before proceeding with further characterizations.

The $\mathrm{CoO}_{x}$ catalyst for control samples was photoelectrodeposited with the same procedure as the $\mathrm{CoFeO}_{x}$ except that no iron(III) sulfate was added to the deposition solution.

$\mathrm{CoFeO}_{\mathrm{x}}$ was electrodeposited by LSV either from 1.7 to $2.0 \mathrm{~V}$ vs RHE (scan rate $10 \mathrm{mV} \mathrm{s}^{-1}$ ), from 1.1-1.7 V vs RHE (scan rate 200 $\mathrm{mV} \mathrm{s}^{-1}$ ) or from 1.8-2.4 V vs RHE (scan rate $200 \mathrm{mV} \mathrm{s}^{-1}$ ). Those conditions were chosen according to our previous work on electrodeposited metal oxides (for the 1.7-2.0 V vs RHE deposition) ${ }^{15}$ and based on the photoelectrodeposited conditions previously described in this section (1.1-1.7 and 1.8$2.4 \mathrm{~V}$ vs RHE) by correcting the potential window with the 
measured photovoltage (ca. $0.7 \mathrm{~V}$, vide infra). The $\mathrm{NiFeO}_{\mathrm{x}}$ and Co-Pi catalysts were deposited on APCVD nanostructured hematite with photoelectrodeposition methods described previously by our group. ${ }^{12,20}$

\subsection{Characterization}

SEM images were obtained with a Zeiss Merlin microscope operated at $2 \mathrm{kV}$ and equipped with an Inlens secondary electron detector. TEM and STEM-EDX images were recorded with a FEl Talos operated at $200 \mathrm{kV}$. TEM samples were prepared by drop-drying a solution containing the hematite particles onto carbon-coated copper grids. The solution was obtained by sonicating a piece of the hematite sample twice for 30 minutes in $\mathrm{MeOH}$.

XPS analysis was carried out using a PHI VersaProbe II scanning XPS microprobe equipped with a monochromatic Al K $\alpha$ source of $24.8 \mathrm{~W}$ with a beam size of $100 \mu \mathrm{m}$. The adventitious carbon 1s peak was calibrated at $284.8 \mathrm{eV}$ and used as an internal standard to compensate for charging effects. Data were fitted by using PHI MultiPak software.

Photoluminescence measurements were obtained with a Horiba Fluorolog 3-22 spectrofluorometer using a $520 \mathrm{~nm}$ excitation wavelength ( $5 \mathrm{~nm}$ bandpass at entrance and exit) and front face detection with a standard photomultiplier detector. The emission was scanned from 550 to $780 \mathrm{~nm}$ (1 nm increment and $0.1 \mathrm{~s}$ integration time).

\subsection{Electrochemical impedance spectroscopy measurements}

The electrochemical impedance spectroscopy (EIS) response of the different hematite photoanodes was measured between 0.7 and $1.4 \mathrm{~V}$ vs RHE every $25 \mathrm{mV}$ in $1 \mathrm{M} \mathrm{KOH}$ solution under simulated AM 1.5G illumination. The photoanode was let to stabilize for $60 \mathrm{~s}$ between each potential step. The EIS response was recorded from $100,000 \mathrm{~Hz}$ to $0.1 \mathrm{~Hz}$ with 8 points per decade. The data were fitted with Zview software.

\subsection{Faradaic efficiency measurements}

The faradaic yield was evaluated by using an optical fluorescence sensor (Ocean Optics) and an airtight glass $\mathrm{H}$-cell. The cell was purged with $\mathrm{N}_{2}$ prior to the measurement in order to have an $\mathrm{O}_{2}$ content lower than $0.5 \%$. The measurement was done at $1.23 \mathrm{~V}$ vs RHE in $1 \mathrm{M} \mathrm{KOH}$.

\section{Results and discussion}

\subsection{Activity of $\mathrm{CoFeO}_{x}$-coated hematite}

In this study, all hematite photoanodes were coated with a thin layer of $\mathrm{Al}_{2} \mathrm{O}_{3}$ by atomic layer deposition (ALD) and are referred to as $\mathrm{Fe}_{2} \mathrm{O}_{3} / \mathrm{Al}_{2} \mathrm{O}_{3}$. Deposition of a thin oxide layer, such as $\mathrm{Al}_{2} \mathrm{O}_{3}$, $\mathrm{Ga}_{2} \mathrm{O}_{3}$, and $\ln _{2} \mathrm{O}_{3}$, on top of hematite photoanodes has been demonstrated to be an efficient strategy to decrease the density of surface trap states and enhance the photoactivity. ${ }^{22,23}$ The beneficial effect of the $\mathrm{Al}_{2} \mathrm{O}_{3}$ layer on the activity of hematite is shown in Fig. 1 , as seen by a cathodic shift of the onset potential induced by $\mathrm{Al}_{2} \mathrm{O}_{3}$. Coating the surface of hematite with an OER catalyst can further increase the photoactivity. Fig. 1 also shows the photoactivity of hematite

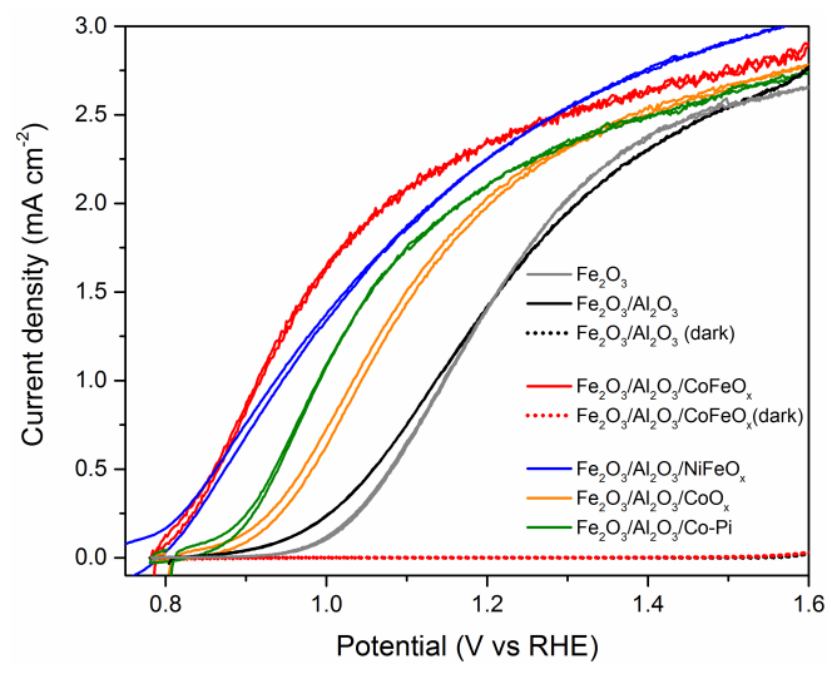

Fig. 1 Polarization curves in $1 \mathrm{M} \mathrm{KOH}$ of $\mathrm{Fe}_{2} \mathrm{O}_{3}$ and $\mathrm{Fe}_{2} \mathrm{O}_{3}$ coated with $\mathrm{Al}_{2} \mathrm{O}_{3}$ and different OER catalysts under simulated AM1.5 illumination (lines) and in the dark (dots). Scan rate $10 \mathrm{mV} \mathrm{s}^{-1}$

coated with different photoelectrodeposited OER catalysts. The onset potential (see experimental details) ${ }^{20}$ for the hematite coated with $\mathrm{CoFeO}_{x}$ is close to $0.8 \mathrm{~V}$ vs $\mathrm{RHE}$, which represents a cathodic shift of approximately $200 \mathrm{mV}$ upon addition of the catalyst layer. These values are similar to the ones when the hematite photoanode is coated with $\mathrm{NiFeO}_{x}$. In comparison, the Co-Pi catalyst has here an onset potential of only $\sim 0.9 \mathrm{~V}$ vs RHE. A similar value was obtained with a control hematite sample coated with $\mathrm{CoO}_{x}$. At applied potentials of 1.0 and $1.23 \mathrm{~V}$ vs RHE, the catalyst-free hematite yields a photocurrent density of 0.2 and $1.6 \mathrm{~mA} \mathrm{~cm}{ }^{2}$, respectively. After electrodepositing $\mathrm{CoFeO}_{x}$, photocurrent densities of 1.6 and $2.5 \mathrm{~mA} \mathrm{~cm} \mathrm{~cm}^{2}$ were obtained at the same potentials, corresponding to a 7 - and 1.5 -fold increase, respectively. In addition, when compared to $\mathrm{NiFeO}_{x}$ at potentials between 0.8 and $1.23 \mathrm{~V}$ vs RHE, the hematite photoanode coated with $\mathrm{CoFeO}_{x}$ has a better fill factor. A comparison with other hematite photoanodes coated with cobalt-based catalysts is presented in Table S1 (ESI). Photoelectrodepostion of $\mathrm{CoFeO}_{x}$ yielded better activity compared to electrodeposited $\mathrm{CoFeO}_{x}$ (Fig. S1 ESI). This can be explained by the fact that, due to the morphology of APCVD hematite being composed of highly branched nanostructures towards the electrolyte and more compact stems near the FTO substrate, electrodeposition will likely preferentially deposit $\mathrm{CoFeO}_{x}$ near the FTO, but the photoactivity primarily arises from the fine branched structure in the front side.

In our study, the observed photocurrent densities (especially the plateau photocurrent density above $1.2-1.4 \mathrm{~V}$ vs RHE) are slightly lower than the ones reported in previous studies using APCVD hematite because the methodology used to delimit the surface area is different from the one used previously (using epoxy glue, instead of an aperture mask, gives a more accurate illuminated area). ${ }^{6,24}$ 


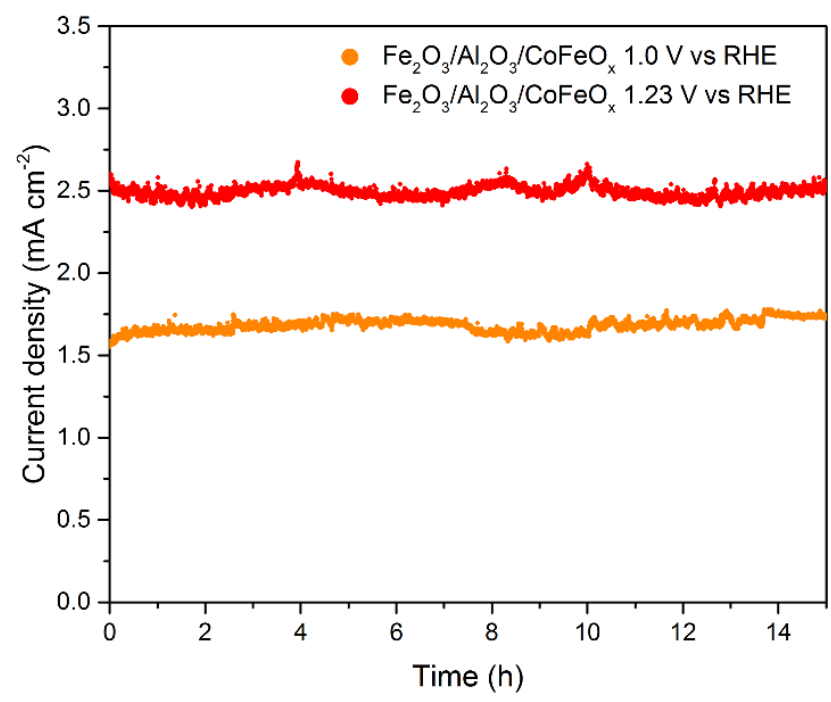

Fig. 2 Constant potential photoelectrolysis at 1.0 and $1.23 \mathrm{~V}$ vs RHE of the $\mathrm{CoFeO}_{x}$ coated hematite during 15 hours under AM1.5 illumination in $1 \mathrm{M} \mathrm{KOH}$.

The optimal performance was reached when the $\mathrm{CoFeO}_{x}$ was photoelectrodeposited with 5 cycles of linear sweep voltammetry (LSV) (Fig. S2 ESI). Shorter or longer depositions (2, 3 , and 8 LSV sweeps) yielded a more anodic onset potential. The stability of the $\mathrm{CoFeO}_{x}$-coated hematite anodes also strongly depended on the number of LSV sweeps (Fig. S3 ESI). With 2 LSV sweeps, a loss of $27 \%$ of the initial photocurrent occurred in the first $30 \mathrm{~min}$ of electrolysis at a constant applied potential of 1.0 $\checkmark$ vs RHE under simulated sunlight (AM1.5). With 3 LSV sweeps, the deactivation was reduced to a photocurrent loss of $12 \%$ in 3 hours. When slightly thicker layers were applied, 5 and 8 LSV sweeps, the deactivation after 3 hours was reduced to 3 and $2 \%$, respectively.

Another important factor to consider when developing overlayers for light absorbers is their optical transparency, especially in the case of APCVD hematite photoanodes, which require front-side illumination for optimal performance. ${ }^{9,25}$ Our photoelectrochemical deposition method allowed us to obtain ultrathin layers of $\mathrm{CoFeO}_{\mathrm{x}}$, and negligible parasitic light absorption from the $\mathrm{CoFeO}_{x}$ layers was observed when deposited with 5 LSV sweeps or less (Fig. S4 ESI). Consequently, this material is effectively optically transparent at its optimal thickness for PEC water oxidation. All further experiments herein were performed with hematite photoanodes coated with 5 LSV sweeps of $\mathrm{CoFeO}_{x}$, unless noted otherwise. Long- term electrolysis of this material was done at 1.0 and $1.23 \mathrm{~V}$ vs RHE under AM1.5 illumination. In both cases, negligible loss of photocurrent after 15 hours was observed, as shown in Fig. 2. Furthermore, the faradaic efficiency for OER of the $\mathrm{CoFeO}_{x^{-}}$ coated hematite photoanode was measured to be close to $100 \%$ at $1.23 \mathrm{~V}$ vs RHE (Fig. S5 ESI).

\subsection{Characterization of $\mathrm{CoFeO}_{\mathrm{x}}$ overlayer}

The chemical composition of the $\mathrm{CoFeO}_{\mathrm{x}}$ overlayer was probed by X-ray photoelectron spectroscopy (XPS). The Co $2 p_{3 / 2}$ signal can be observed at a binding energy (BE) of $780.4 \mathrm{eV}$ after deconvolution of the high-resolution spectrum between 775 and $795 \mathrm{eV}$ (Fig. 3a). This $\mathrm{BE}$ indicates that $\mathrm{Co}$ is in the +2 oxidation state in the form of $\mathrm{Co}(\mathrm{OH})_{2} .{ }^{26}$ This result is in accordance with our previous study on oxidatively electrodeposited $\mathrm{CoFeO}_{\mathrm{x}}{ }^{15} \mathrm{~A}$ broad signal peaking at $784.7 \mathrm{eV}$ is ascribed to the Fe $\mathrm{L}_{3} \mathrm{M}_{45} \mathrm{M}_{45}$ Auger line. The high intensity of the Fe LMM Auger line, compared to the Co $2 p_{3 / 2}$ signal, indicates that the layer of $\mathrm{CoFeO}_{x}$ is thinner than the penetration depth of X-ray (tens of angstroms) and that the Fe LMM signal arises from the hematite substrate. ${ }^{27}$ This is further confirmed by looking at the Fe $2 p$ high-resolution spectra (Fig. $3 b)$. The spectrum of the $2 p_{3 / 2}$ signal has two distinct peaks separated by $1 \mathrm{eV}$ (BE 710.7 and $709.7 \mathrm{eV}$ ), as well as a prominent satellite band $8 \mathrm{eV}$ above the $2 \mathrm{p}_{3 / 2}$ signal (BE 718.5 $\mathrm{eV}$ ), which is characteristic of $\alpha-\mathrm{Fe}_{2} \mathrm{O}_{3}{ }^{28}$ Another peak at 712.5 $\mathrm{eV}$ is representative of $\mathrm{Fe}^{3+}$ in $\mathrm{FeOOH}$. Both of these iron oxides can be confirmed by looking at the $\mathrm{O} 1 \mathrm{~s}$ spectrum in Fig. 3c. Two peaks can be observed at BE of $531.3 \mathrm{eV}$ and $529.7 \mathrm{eV}$ which can be assigned to $\mathrm{O}^{2-}$ in a hydroxyl environment and in $\mathrm{Fe}_{2} \mathrm{O}_{3}$, respectively. The Fe LMM Auger signal is also visible in the highresolution spectrum of the Co $2 p$ region of the catalyst-free hematite (Fig. S6a ESI). The FeOOH peak cannot be attributed to the layer of $\mathrm{CoFeO}_{x}$ as it is also present in the $2 p$ region of the catalyst-free hematite spectrum (Fig. S6b ESI). Moreover, in the $\mathrm{O} 1 \mathrm{~s}$ region (Fig. $\mathrm{S} 6 \mathrm{c} \mathrm{ESI}$ ) the $\mathrm{O}^{2-}$ signals at $\mathrm{BE} 531.3 \mathrm{eV}$ indicates that $\mathrm{FeOOH}$ is also present on the surface of the $\mathrm{Fe}_{2} \mathrm{O}_{3}$ nanostructure.

The layer of $\mathrm{CoFeO}_{x}$ is too thin to be visible by SEM and no morphological differences were observed between a photoanode coated with $\mathrm{CoFeO}_{x}$ (5 LSV sweeps) and a catalystfree hematite photoanode (Fig. S7 ESI). HR-TEM was used to determine the thickness of the $\mathrm{CoFeO}_{x}$ layer on hematite
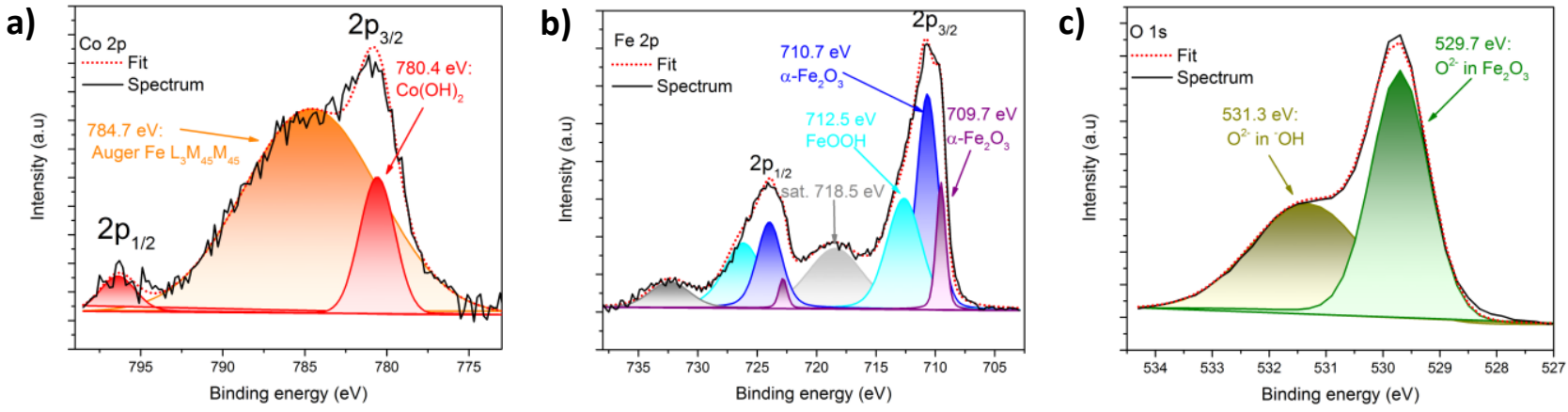

Fig. 3 XPS spectra of the $\mathrm{CoFeO}_{x}$-coated hematite ( $5 \mathrm{LSV}$ ) with high-resolution spectra of a) Co $2 \mathrm{p}$ region, b) Fe $2 \mathrm{p}$ region and c) $\mathrm{O} 1 \mathrm{~s}$ region, showing fits to spectra by deconvolution. 
a)

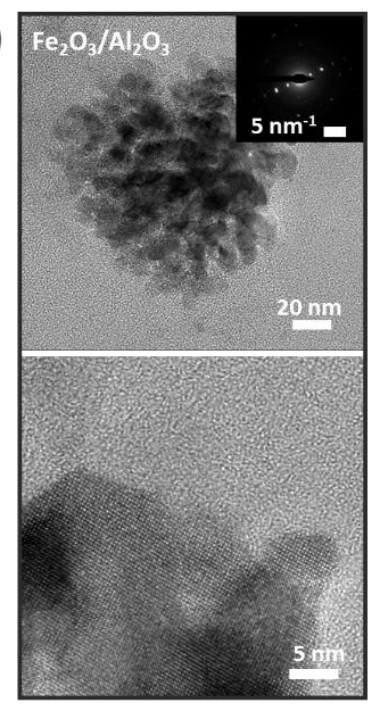

d)

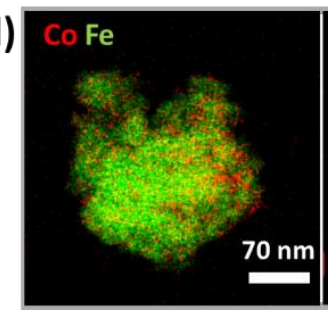

b)

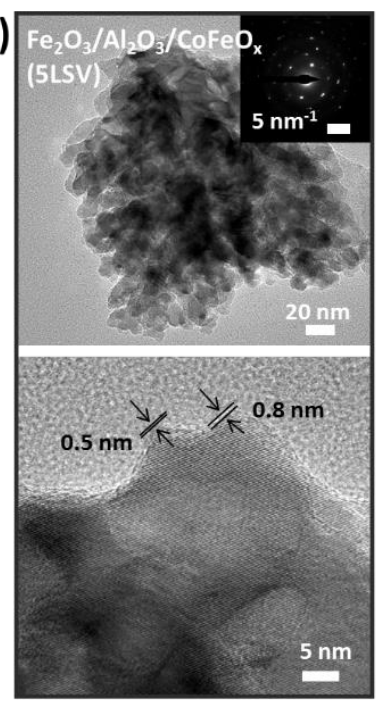

c)
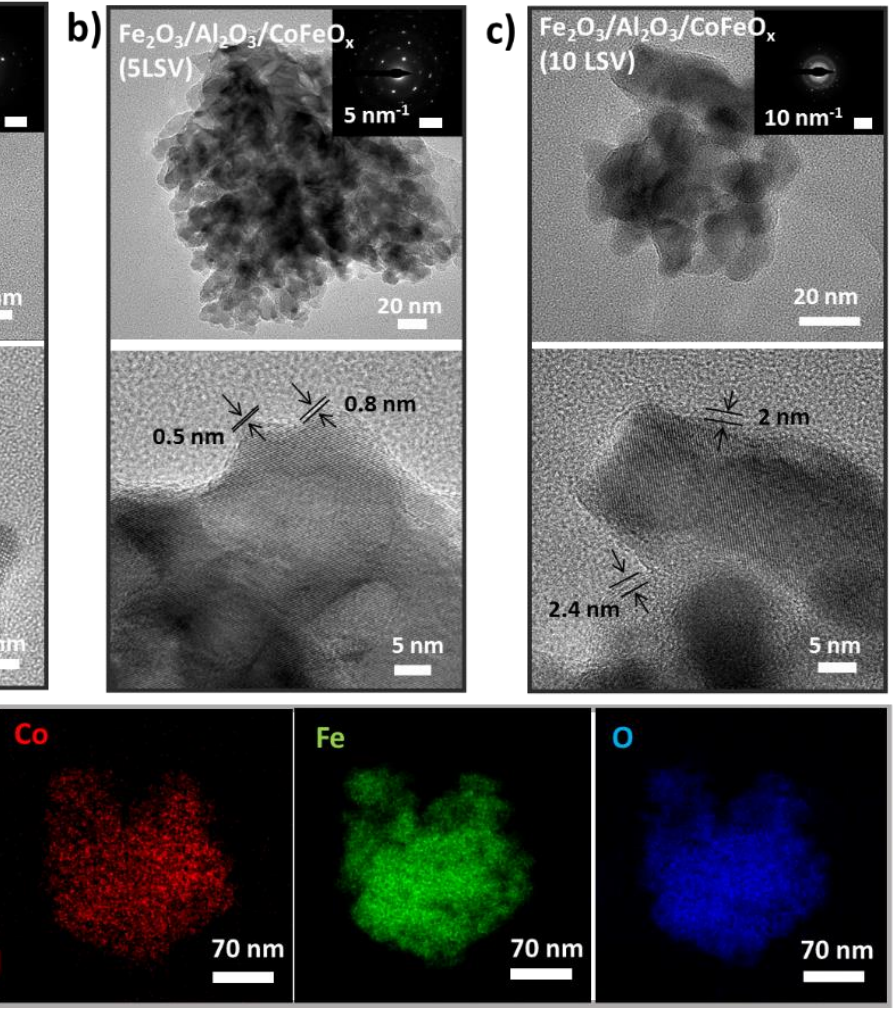

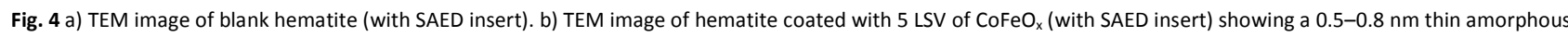
$\mathrm{CoFeO}_{x}$ layer. c) TEM image of hematite coated with $10 \mathrm{LSV}_{\text {of }} \mathrm{CoFeO}_{x}$ (with SAED insert), showing a 2-2.4 nm amorphous CoFeO layer. d) STEM-EDX mapping (CoFe, Co, $\mathrm{Fe}$, and $\mathrm{O}$ ) of hematite coated with $5 \mathrm{LSV}$ of $\mathrm{CoFeO}_{x}$, showing the homogeneous dispersion the $\mathrm{CoFeO}_{x}$ layer.

nanoparticles that were ultrasonically detached from the electrode substrate. This analysis further confirmed that the oxide layer is indeed present, but very thin. Without $\mathrm{CoFeO}_{x}$ deposited, the edges of the hematite crystal lattice are sharp and clear (Fig. 4a). As ALD of $\mathrm{Al}_{2} \mathrm{O}_{3}$ is known to result in islandtype growth during the initial deposition cycles, the $\mathrm{Al}_{2} \mathrm{O}_{3}$ layer here is likely not visibly distinguishable due to the low number of ALD cycles used in this study (6 cycles). ${ }^{29}$ When a layer of $\mathrm{CoFeO}_{\mathrm{x}}$ is photoelectrodeposited with 5 LSV sweeps, the HRTEM images show that a thin amorphous layer of $0.5-0.8 \mathrm{~nm}$ is visible on the edge of the hematite nanocrystals (Fig. 4b). After deposition of a thicker layer of $\mathrm{CoFeO}_{x}$ (10 LSV sweeps) the amorphous layer on top of the hematite crystals is visible with a thickness of ca. 2-2.4 nm (Fig. 4c). The slight variation in thickness of the $\mathrm{CoFeO}_{x}$ layer is likely due to the photoelectrodeposition method that preferentially deposits $\mathrm{CoFeO}_{x}$ only where holes reach the surface. STEM-EDX was used to map the distribution of Co atoms on top of the hematite. As seen in Fig. 4d, the EDX mapping confirms that Co is homogeneously dispersed on the hematite particle. The Fe and $\mathrm{O}$ signals are expected to largely arise from the underlying hematite. High magnification STEM-EDX characterization of the $\mathrm{CoFeO}_{x}$-coated hematite also revealed that the concentration of Co was higher on the edge of the particles (as seen in the EDX map and with the intensity of the Co K $\alpha_{1}$ and $\mathrm{Fe} K \beta_{1}$ lines in Fig. S8a and b ESI), supporting the fact that the amorphous layer visible on the edge of the hematite crystals is the $\mathrm{CoFeO}_{x}$ layer.

\subsection{Role of $\mathrm{CoFeO}_{x}$}

Despite $\mathrm{CoFeO}_{x}$ being known as a highly active OER catalyst in other systems, we sought to establish whether this material enhances the PEC performance of hematite only by accelerating the kinetics of water oxidation, or also by acting on other aspects, such as suppressing electron-holes recombination on surface trap states, or by modifying thermodynamics of the system, such as modifying the hematite flat-band potential. ${ }^{16,30,31}$ To reveal the role of the $\mathrm{COFeO}_{x}$ coating on PEC performance, we first measured the charge separation efficiency $\left(\eta_{\text {sep }}\right)$ and charge injection efficiency $\left(\eta_{\text {inj }}\right)$ using the method developed by Dotan et al., which uses hydrogen peroxide as a hole scavenger (see Fig. S9 ESI and explanation in ESI text). ${ }^{32}$ The $\mathrm{CoFeO}_{x}$ layer promotes charge injection efficiency of the holes at the semiconductor/electrolyte interface, as shown in Fig. 5a. At $1.0 \mathrm{~V}$ vs $\mathrm{RHE}$, the charge injection efficiency is increased from $15 \%$ for $\mathrm{Fe}_{2} \mathrm{O}_{3} / \mathrm{Al}_{2} \mathrm{O}_{3}$ to $57 \%$ for $\mathrm{Fe}_{2} \mathrm{O}_{3} / \mathrm{Al}_{2} \mathrm{O}_{3} / \mathrm{CoFeO}_{x}$. This significant increase in $\eta_{\text {inj }}$ can arise either from faster OER kinetics or from slower recombination. ${ }^{33}$ Additionally, at approximately $1.15 \mathrm{~V}$ vs RHE when $\mathrm{CoFeO}_{x}$ is present, $\eta_{\text {inj }}$ reaches its maximum value and plateaus. This indicates that both photocurrents, in standard 1 $\mathrm{M} \mathrm{KOH}$ and in $1 \mathrm{M} \mathrm{KOH}+0.5 \mathrm{M} \mathrm{H}_{2} \mathrm{O}_{2}$ (Fig. S9c and d ESI), converge and the applied potential is high enough to suppress recombination at surface trap states. Interestingly, when looking at the charge separation efficiency, displayed in Fig. 5b, two trends can be observed. Above $0.85 \mathrm{~V}$ vs $\mathrm{RHE}$, the $\mathrm{CoFeO}_{x}$ layer does not influence the separation efficiency of the hematite. This is expected as only the surface properties should be influenced by the deposition of this oxide overlayer and 
charge dynamics in the bulk of hematite remain unaffected. However, at potentials lower than 0.85 V vs $\mathrm{RHE}, \mathrm{CoFeO}_{x}$-coated hematite has a lower charge separation efficiency than the catalyst-free hematite, which could arise from increased interfacial recombination. In contrast to previous reports of cobalt-based catalysts on photoanodes, ${ }^{18,34}$ the charge separation results here suggest that $\mathrm{CoFeO}_{x}$ does not enhance charge separation in the bulk by the formation of a $p-n$ junction and certainly does not account for improved PEC performance with the $\mathrm{CoFeO}_{x}$ coating.

We also used photoluminescence (PL) in order to establish whether the $\mathrm{CoFeO}_{x}$ coating could passivate hematite surface states, ${ }^{18,35}$ which also could potentially account for the observed cathodic shift in onset potential. As deposited here, the $\mathrm{Al}_{2} \mathrm{O}_{3}$ layer is expected to only partially passivate the surface states of hematite as this layer is not expected to be fully conformal, owing to the low number of ALD cycles used. Thus, some surface trap states of hematite could still be present and subsequently be passivated when $\mathrm{CoFeO}_{x}$ is deposited. Typically, photoluminescence is not observed in bulk hematite. After absorption of a photon with energy greater than the bandgap, photo-generated electron-hole pairs recombine in a non-radiative process due to efficient lattice and magnetic relaxation pathways. ${ }^{22}$ However, photoluminescence has been observed in nanocrystalline hematite capped with specific surface agents and is largely dependent on the surface quality and especially on the density of trap states. ${ }^{36}$ Consequently, if the $\mathrm{CoFeO}_{\mathrm{x}}$ layer is passivating surface states, photoluminescence emission is expected to increase. Here, no difference in photoluminescence emission was observed before and after the deposition of the $\mathrm{CoFeO}_{x}$ layer on blank hematite or on $\mathrm{Fe}_{2} \mathrm{O}_{3} / \mathrm{Al}_{2} \mathrm{O}_{3}$ (Fig. S10a and b ESI). We therefore rule out that the cathodic shift of onset potential induced by the $\mathrm{CoFeO}_{x}$ is due to a significant passivation of surface states. Moreover, when comparing the photoactivity of $\mathrm{Fe}_{2} \mathrm{O}_{3} / \mathrm{CoFeO}_{x}$ and $\mathrm{Fe}_{2} \mathrm{O}_{3} / \mathrm{Al}_{2} \mathrm{O}_{3} / \mathrm{CoFeO}_{x}$, the onset potential is the same but a difference of fill factor is visible (Fig. S10c ESI). When $\mathrm{Al}_{2} \mathrm{O}_{3}$ is deposited, a higher fill factor is obtained and the photocurrent density is increased from 1.2 to $1.6 \mathrm{~mA} \mathrm{~cm}^{-2}$ at $1.0 \mathrm{~V}$ vs RHE. This result suggests that $\mathrm{CoFeO}_{x}$ and $\mathrm{Al}_{2} \mathrm{O}_{3}$ play distinctive roles that have a synergetic effect in the enhancement of the hematite photoactivity.

Finally, Wang et al. recently reported that the cathodic shift induced on hematite by transition metal oxides layers such as $\mathrm{NiFeO}_{x}$ was due to an increase in photovoltage, owing to a reduction of the surface Fermi level pinning effect. ${ }^{37}$ However, we do not observed this effect in our system with $\mathrm{CoFeO}_{x}$, as blank and $\mathrm{CoFeO}_{x}$-coated anodes produced similar photovoltages of 0.74 and $0.76 \mathrm{~V}$, respectively (Fig. S11 ESI). Electrochemical impedance spectroscopy (EIS) under illumination was used to further probe the PEC behavior of $\mathrm{CoFeO}_{x}$ on hematite. The impedance data were fitted by using an equivalent circuit developed by Klahr et al. and widely used for hematite photoanodes (inset in Fig. S12d ESI). ${ }^{11,19,38-41}$ The equivalent circuit includes a space-charge capacitance of the bulk hematite $\left(C_{s c}\right)$, a capacitance of the surface states $\left(C_{s s}\right)$, a solution resistance $\left(R_{s}\right)$, a resistance to electron-hole recombination via surface states $\left(R_{\text {rec }}\right)$, as well as a charge- transfer resitance $\left(R_{c t}\right)$. At different potentials, a change in the charge-transfer region of the Bode Plot (frequencies between 0.1 and $10 \mathrm{~Hz}$ ) occurs for both $\mathrm{Fe}_{2} \mathrm{O}_{3} / \mathrm{Al}_{2} \mathrm{O}_{3}$ and $\mathrm{Fe}_{2} \mathrm{O}_{3} / \mathrm{Al}_{2} \mathrm{O}_{3} / \mathrm{CoFeO}_{x}$ (Fig. S12a ESI). In the Nyquist plot, shown in Fig. 6, the low-frequency semicircle usually associated with the charge-transfer resistance is clearly smaller for the $\mathrm{CoFeO}_{x^{-}}$ coated anodes compared to the catalyst-free hematite. This translates into a reduction of $\mathrm{R}_{\mathrm{ct}}$ by approximately one order of magnitude in the onset potential region when $\mathrm{CoFeO}_{x}$ is present (Fig. S12b ESI). The recombination resistance, $\mathrm{R}_{\text {rec, }}$ remains on
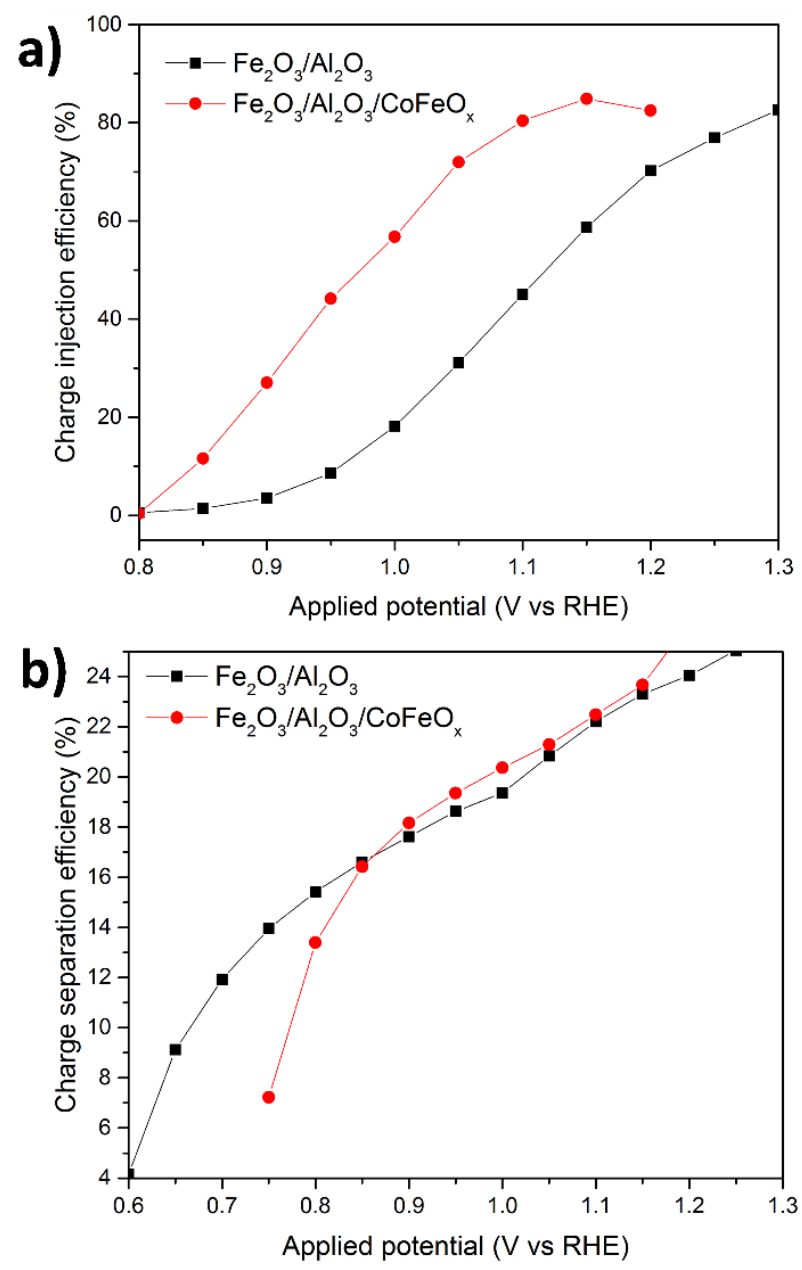

Fig. 5 a) Charge injection efficiency showing an increased efficiency when $\mathrm{CoFeO}_{x}$ is deposited and b) charge separation efficiency of blank hematite and $\mathrm{CoFeO}_{x}$-coated hematite.

the same order of magnitude between the catalyst-free and $\mathrm{CoFeO}_{x}$-coated anodes (Fig. S12b ESI). The charge-transfer rate constant $k_{\mathrm{ct}}$ can be obtained by the reciprocal of the time constant, $\tau$, of the $\mathrm{R}_{\mathrm{ct}} \mathrm{C}_{\mathrm{ss}}$ unit $\left(\tau=\mathrm{R}_{\mathrm{ct}} \cdot \mathrm{C}_{\mathrm{ss}} ; k_{\mathrm{ct}}=\left(\mathrm{R}_{\mathrm{ct}} \cdot \mathrm{C}_{\mathrm{ss}}\right)^{-1}\right) .{ }^{42}$ When $\mathrm{CoFeO}_{\mathrm{x}}$ is deposited, $k_{\mathrm{ct}}$ increases in the $0.8-1.1 \mathrm{~V}$ vs $\mathrm{RHE}$ region compared to catalyst-free hematite (Fig. S12c ESI), indicating that $\mathrm{CoFeO}_{x}$ increases the oxidation reaction rate on the surface of the hematite photoanode in the onset potential region. The capacitance of the surface states $\mathrm{C}_{\mathrm{ss}}$ shows a peak for both $\mathrm{CoFeO}_{x}$-coated and catalyst-free hematite, correlating with the rise of the photocurrent for both photoanodes (Fig. S12d ESI). By definition, the capacitance is related to the ability of a material to hold charges. In our case, the magnitude of $\mathrm{C}_{\mathrm{ss}}$ for the coated hematite is higher than for without catalyst, 
suggesting that $\mathrm{CoFeO}_{x}$ does not suppress but rather increases the concentration of surface states, possibly by forming oxidized intermediates that can act as more efficient shuttles for transferring the holes into the electrolyte. We used the obtained $\mathrm{C}_{\mathrm{sc}}$ values in a Mott Schottky plot (Fig. S12e ESI) to investigate if $\mathrm{CoFeO}_{x}$ could induce a shift in the flat-band potential. Nyquist plots taken in the dark (inset in Fig. 6) show only one semicircle and were fitting by a simple Randles circuit (inset in Fig. S12e ESI). ${ }^{41}$ The obtained Mott Shottky plots, also measured in the dark, were super linear. Ilkay et al. explained this curvature for the APCVD hematite as a decrease of the active surface area, contributing to a change in capacitance due to depletion of the smallest features and the curvature of the nanocrystals surface as the applied voltage changes. ${ }^{9}$ The fitting of $\mathrm{C}_{\mathrm{sc}}{ }^{-2}$ was done from 0.7 to $0.85 \mathrm{~V}$ vs RHE. This potential range was chosen in our analysis as Mott Schottky assumption of a flat surface is best approximated when the space charge layer is thin, close to the flat-band potential. In order fit the data, a roughness factor of 20 was taken into account to calculate the total surface that is in contact with the electrolyte from the geometrical surface area. ${ }^{9}$ Both $\mathrm{CoFeO}_{\mathrm{x}}$-coated and catalystfree hematite yield a flat-band potential close to $0.45 \mathrm{~V}$ vs RHE, which is similar to values reported previously for the APCVD hematite. ${ }^{9}$ Thus, the $\mathrm{CoFeO}_{x}$ layer shifts the photocurrent onset potential while leaving the flat-band potential unchanged. Finally, in order to confirm the validity of the fitting of the EIS measurements, the total resistance from impedance $\left(R_{\text {tot }}=R_{s}+\right.$ $R_{\text {rec }}+R_{c t}$ ) was plotted and compared to the resistance obtained from the derivative of the polarization curves $\left(R_{\text {tot }}=d V / d \mathrm{~J}\right)$. For both $\mathrm{CoFeO}_{x}$-coated and catalyst-free hematite, $\mathrm{R}_{\text {tot }}$ matches reasonably well (Fig. S12f ESI).

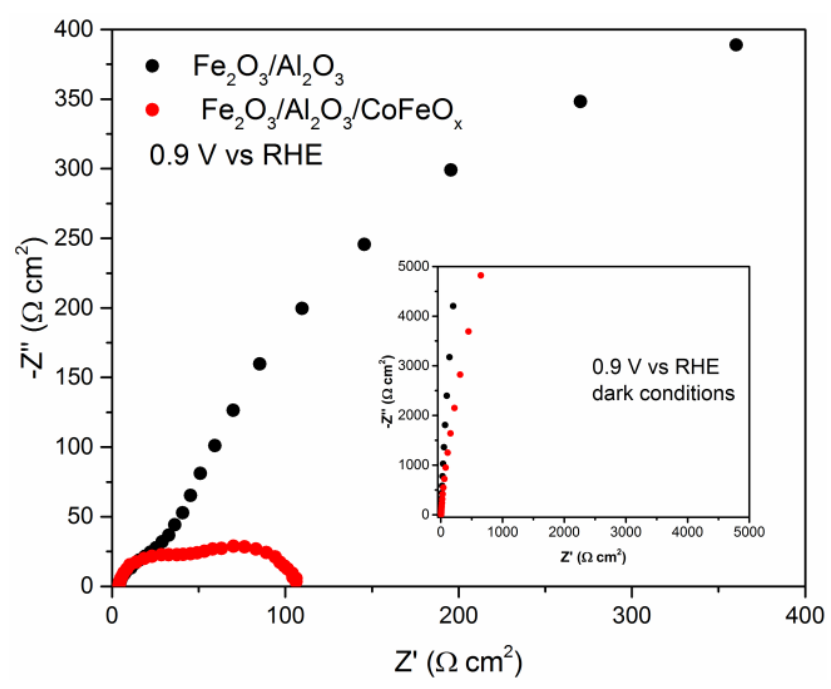

Fig. 6 Nyquist plot of $\mathrm{Fe}_{2} \mathrm{O}_{3} / \mathrm{Al}_{2} \mathrm{O}_{3}$ and $\mathrm{Fe}_{2} \mathrm{O}_{3} / \mathrm{Al}_{2} \mathrm{O}_{3} / \mathrm{CoFeO}_{\mathrm{x}}$ at $0.9 \mathrm{~V}$ vs RHE in $1 \mathrm{M} \mathrm{KOH}$ and under illumination and in the dark (inset).

\section{Conclusions}

Motivated by the high electrocatalytic activity of the oxidatively electrodeposited $\mathrm{CoFeO}_{x}$ OER catalyst, we developed a photoelectrodeposition method to apply this oxide on APCVD nanostructured hematite photoanodes. The optimized deposition yielded an amorphous, ultrathin $(<1 \mathrm{~nm})$ and optically transparent layer providing a substantial 200-mV cathodic shift of the photocurrent onset potential and a stable 7-fold increase in photocurrent density at $1.0 \mathrm{~V}$ VS RHE compared to the catalyst-free hematite, making it among the most active hematite photoanodes reported to date. The $\mathrm{CoFeO}_{x}$ increased the charge injection efficiency at the semiconductor/electrolyte interface by reducing the chargetransfer resistance. Moreover, neither passivation of the surface states by $\mathrm{CoFeO}_{x}$, nor modification of the flat-band potential or photovoltage were observed upon deposition of $\mathrm{CoFeO}_{x}$. Together, these results suggest that the enhancement of the PEC activity due to the $\mathrm{CoFeO}_{x}$ layer purely arise from a catalytic effect.

\section{Conflicts of interest}

There are no conflicts to declare

\section{Acknowledgements}

This project has received funding from the European Research Council (ERC) under the European Union's Horizon 2020 research and innovation programme (grant agreement $\mathrm{n}^{\circ}$ 681292 , to $\mathrm{XH}$ ), the PECHouse3 project from the Swiss Federal Office of Energy (no. SI/500090-03, to M.G. and J.L.), and the Chinese Thousand Talents Program for Young Professionals (to J.L.).

The authors thank Lichen Bai (EPFL) for the HR-TEM measurements. Jordan Katz gratefully acknowledges the Denison University Research Foundation for its support.

\section{Notes and references}

1 Lewis, N. S. \& Nocera, D. G. Powering the planet: Chemical challenges in solar energy utilization. Proceedings of the National Academy of Sciences of the United States of America 103, 15729-15735 (2006).

2 Tachibana, Y., Vayssieres, L. \& Durrant, J. R. Artificial photosynthesis for solar water-splitting. Nature Photonics 6, 511, doi:10.1038/nphoton.2012.175 (2012).

3 Walter, M. G. et al. Solar water splitting cells. Chemical reviews 110, 6446-6473 (2010).

4

Licht, S. et al. Efficient Solar Water Splitting, Exemplified by RuO2-Catalyzed AlGaAs/Si Photoelectrolysis. The Journal of Physical Chemistry $B$ 104, 8920-8924, doi:10.1021/jp002083b (2000).

5 Sivula, K., Le Formal, F. \& Grätzel, M. Solar Water Splitting: Progress Using Hematite ( $\alpha$-Fe203) Photoelectrodes. ChemSusChem 4, 432-449, doi:doi:10.1002/cssc.201000416 (2011).

6 Kay, A., Cesar, I. \& Grätzel, M. New Benchmark for Water Photooxidation by Nanostructured $\alpha$-Fe2O3 
Films. Journal of the American Chemical Society 128, 18 15714-15721, doi:10.1021/ja064380l (2006).

Wheeler, D. A., Wang, G., Ling, Y., Li, Y. \& Zhang, J. Z. Nanostructured hematite: synthesis, characterization, charge carrier dynamics, and photoelectrochemical properties. Energy \& Environmental Science 5, 66826702, doi:10.1039/C2EE00001F (2012).

Sivula, K. Nanostructured $\alpha$-Fe2O3 photoanodes: In Van de Krol R. and Grätzel M. Photoelectrochemical Hydrogen Production. (Springer, 2012).

Cesar, I., Sivula, K., Kay, A., Zboril, R. \& Grätzel, M. Influence of Feature Size, Film Thickness, and Silicon Doping on the Performance of Nanostructured Hematite Photoanodes for Solar Water Splitting. The Journal of Physical Chemistry C 113, 772-782, doi:10.1021/jp809060p (2009).

Shen, S., Lindley, S. A., Chen, X. \& Zhang, J. Z. Hematite heterostructures for photoelectrochemical water splitting: rational materials design and charge carrier dynamics. Energy \& Environmental Science 9, 27442775, doi:10.1039/C6EE01845A (2016).

Riha, S. C. et al. Atomic Layer Deposition of a Submonolayer Catalyst for the Enhanced Photoelectrochemical Performance of Water Oxidation with Hematite. Acs Nano 7, 2396-2405, doi:10.1021/nn305639z (2013).

Morales-Guio, C. G. et al. An Optically Transparent Iron Nickel Oxide Catalyst for Solar Water Splitting. Journal of the American Chemical Society 137, 9927-9936 (2015).

Tilley, S. D., Cornuz, M., Sivula, K. \& Grätzel, M. LightInduced Water Splitting with Hematite: Improved Nanostructure and Iridium Oxide Catalysis. Angewandte Chemie International Edition 49, 64056408 (2010).

Zhong, D. K. \& Gamelin, D. R. Photoelectrochemical Water Oxidation by Cobalt Catalyst ("Co-Pi")/ $\alpha-\mathrm{Fe} 2 \mathrm{O} 3$ Composite Photoanodes: Oxygen Evolution and Resolution of a Kinetic Bottleneck. Journal of the American Chemical Society 132, 4202-4207, doi:10.1021/ja908730h (2010).

Morales-Guio, C. G., Liardet, L. \& Hu, X. Oxidatively Electrodeposited Thin-Film Transition Metal (Oxy)hydroxides as Oxygen Evolution Catalysts. Journal of the American Chemical Society 138, 89468957, doi:10.1021/jacs.6b05196 (2016).

Song, F. et al. Transition Metal Oxides as Electrocatalysts for the Oxygen Evolution Reaction in Alkaline Solutions: An Application-Inspired Renaissance. Journal of the American Chemical Society 140, 7748-7759, doi:10.1021/jacs.8b04546 (2018).

Bhandary, N., Singh, A. P., Ingole, P. P. \& Basu, S. Enhancing the Photoelectrochemical Performance of a Hematite Dendrite/Graphitic Carbon Nitride Nanocomposite through Surface Modification with CoFeOx. ChemPhotoChem 1, 70-75, doi:doi:10.1002/cptc.201600008 (2017).

Yang-Fan, X., Xu-Dong, W., Hong-Yan, C., Dai-Bin, K. \& Cheng-Yong, S. Toward High Performance Photoelectrochemical Water Oxidation: Combined Effects of Ultrafine Cobalt Iron Oxide Nanoparticle. Advanced Functional Materials 26, 4414-4421, doi:doi:10.1002/adfm.201600232 (2016).

19 Zhang, J., García-Rodríguez, R., Cameron, P. \& Eslava, S. Role of cobalt-iron (oxy)hydroxide (CoFeOx) as oxygen evolution catalyst on hematite photoanodes. Energy \& Environmental Science, doi:10.1039/C8EE01346B (2018).

20 Zhong, D. K., Cornuz, M., Sivula, K., Gratzel, M. \& Gamelin, D. R. Photo-assisted electrodeposition of cobalt-phosphate (Co-Pi) catalyst on hematite photoanodes for solar water oxidation. Energy \& Environmental Science 4, 1759-1764 (2011).

21 Dotan, H., Mathews, N., Hisatomi, T., Grätzel, M. \& Rothschild, A. On the Solar to Hydrogen Conversion Efficiency of Photoelectrodes for Water Splitting. The Journal of Physical Chemistry Letters 5, 3330-3334, doi:10.1021/jz501716g (2014).

Le Formal, F. et al. Passivating surface states on water splitting hematite photoanodes with alumina overlayers. Chemical Science 2, 737-743 (2011).

Hisatomi, T. et al. Cathodic shift in onset potential of solar oxygen evolution on hematite by 13 -group oxide overlayers. Energy \& Environmental Science 4, 25122515, doi:10.1039/C1EE01194D (2011).

24 Le Formal, F., Sivula, K. \& Grätzel, M. The Transient Photocurrent and Photovoltage Behavior of a Hematite Photoanode under Working Conditions and the Influence of Surface Treatments. The Journal of Physical Chemistry C 116, 26707-26720, doi:10.1021/jp308591k (2012).

25 Trotochaud, L., Mills, T. J. \& Boettcher, S. W. An Optocatalytic Model for Semiconductor-Catalyst Water-Splitting Photoelectrodes Based on In Situ Optical Measurements on Operational Catalysts. The Journal of Physical Chemistry Letters 4, 931-935, doi:10.1021/jz4002604 (2013).

26 Biesinger, M. C., Lau, L. W. M., Gerson, A. R. \& Smart, R. S. C. Resolving surface chemical states in XPS analysis of first row transition metals, oxides and hydroxides: $\mathrm{Sc}, \mathrm{Ti}, \mathrm{V}, \mathrm{Cu}$ and $\mathrm{Zn}$. Applied Surface Science 257, 887-898, doi:http://dx.doi.org/10.1016/j.apsusc.2010.07.086 (2010).

27 Moulder, J. F. S., W.F.; Sobol, P.E., Bomben, K.D. Handbook of X-ray Photoelectron Spectroscopy. (Physical Electronics, Inc, 1995).

28 Mclntyre, N. S. \& Zetaruk, D. G. X-ray photoelectron spectroscopic studies of iron oxides. Analytical Chemistry 49, 1521-1529, doi:10.1021/ac50019a016 (1977).

29 Naumann, V., Otto, M., Wehrspohn, R. B., Werner, M. \& Hagendorf, C. Interface and Material Characterization of Thin ALD-Al2O3 Layers on Crystalline Silicon. Energy Procedia 27, 312-318, 
doi:https://doi.org/10.1016/j.egypro.2012.07.069 (2012).

McCrory, C. C. L., Jung, S., Peters, J. C. \& Jaramillo, T. F. Benchmarking Heterogeneous Electrocatalysts for the Oxygen Evolution Reaction. Journal of the American Chemical Society 135, 16977-16987, doi:10.1021/ja407115p (2013). Li, C., Luo, Z., Wang, T. \& Gong, J. Surface, Bulk, and Interface: Rational Design of Hematite Architecture toward Efficient Photo-Electrochemical Water Splitting. Advanced Materials 30, 1707502, doi:doi:10.1002/adma.201707502 (2018).

Dotan, H., Sivula, K., Gratzel, M., Rothschild, A. \& Warren, S. C. Probing the photoelectrochemical properties of hematite ([small alpha]-Fe2O3) electrodes using hydrogen peroxide as a hole scavenger. Energy \& Environmental Science 4, 958964, doi:10.1039/COEE00570C (2011).

Luo, Z., Li, C., Liu, S., Wang, T. \& Gong, J. Gradient doping of phosphorus in $\mathrm{Fe} 2 \mathrm{O} 3$ nanoarray photoanodes for enhanced charge separation. Chemical Science 8, 91-100, doi:10.1039/C6SC03707K (2017).

Chang, X. et al. Enhanced Surface Reaction Kinetics and Charge Separation of $p-n$ Heterojunction Co304/BiVO4 Photoanodes. Journal of the American Chemical Society 137, 8356-8359, doi:10.1021/jacs.5b04186 (2015).

Cao, D. et al. Cathodic shift of onset potential for water oxidation on a $\mathrm{Ti} 4+$ doped $\mathrm{Fe} 2 \mathrm{O} 3$ photoanode by suppressing the back reaction. Energy \& Environmental Science 7, 752-759, doi:10.1039/C3EE42722F (2014).

Zou, B. S. \& Volkov, V. Surface modification on timeresolved fluorescences of $\mathrm{Fe} 2 \mathrm{O} 3$ nanocrystals. Journal of Physics and Chemistry of Solids 61, 757-764, doi:https://doi.org/10.1016/S0022-3697(99)00266-8 (2000).

Du, C. et al. Hematite-Based Water Splitting with Low Turn-On Voltages. Angewandte Chemie International Edition 52, 12692-12695, doi:doi:10.1002/anie.201306263 (2013).

Klahr, B., Gimenez, S., Fabregat-Santiago, F., Bisquert, J. \& Hamann, T. W. Photoelectrochemical and Impedance Spectroscopic Investigation of Water Oxidation with "Co-Pi"-Coated Hematite Electrodes. Journal of the American Chemical Society 134, 1669316700, doi:10.1021/ja306427f (2012). Klahr, B., Gimenez, S., Fabregat-Santiago, F., Bisquert, J. \& Hamann, T. W. Electrochemical and photoelectrochemical investigation of water oxidation with hematite electrodes. Energy \& Environmental Science 5, 7626-7636, doi:10.1039/C2EE21414H (2012).
Steier, L. et al. Understanding the Role of Underlayers and Overlayers in Thin Film Hematite Photoanodes. Advanced Functional Materials 24, 7681-7688, doi:doi:10.1002/adfm.201402742 (2014). Peter, L. Kinetics and Mechanisms of Light-Driven Reactions at Semiconductor Electrodes: Principles and Techniques in Photoelectrochemical Water Splitting: Materials, Processes and Architectures p.19-51 (RSC Publishing, 2013). 